\title{
Strategi Pemuridan bagi Narapidana di LP Cipinang Jakarta Timur berdasar pada 2 Timotius 4:2 dan relevansinya bagi pelayanan Misi kaum Marginal
}

\author{
Dr. Matheus Mangentang, M.Th. ${ }^{1}$ Dr. Malik, M.Th. ${ }^{2}$ Tony Salurante, M.Pd.K., MA. Dr. \\ Dyulius Thomas Bilo, M.Th. Moses Wibowo, M.Th., MA. Dr. Jonidius Illu, M.Th. \\ Sekolah Tinggi Teologi Injili Arastamar (SETIA) Jakarta \\ matheusmangentang@sttsetia.ac.id; malikbambangan@sttsetia.ac.id; tony.salurante@sttsetia.ac.id; \\ greatshine@sttsetia.ac.id; mbiwobowo@stt.setia.ac.id; joillu@sttsetia.ac.id
}

\begin{abstract}
Everyone believe is called to be a disciple by Christ. Christianity without discipleship is Christianity without Christ. Departing from this statement, it is understood that, only by becoming a disciple of Christ can one become a light or witness of Christ in the world and lead others to Christ. The true Christian life, is not meant to simply accept Jesus as Savior, attend church services, read the Bible, pray, talk about Jesus, but also is intended to represent God and demonstrate the lifestyle of God's kingdom on earth. So true Christians are disciples of Jesus Christ. Because of the importance of that discipleship, students are mentioned 269 times in the New Testament, which refers to individuals who are jointly committed to following Jesus Christ. The purpose of this research is to provide discipleship services for Christian prisoners at Lembaga Pemasyarakatan Cipinang Jakarta Timur. As a result of this research that after this discipleship was held Christian convicts at Lembaga Pemasyarakatan Cipinang Jakarta Timur had a Christlike character, had hope in Christ, could multiply discipleship.
\end{abstract}

Keywords: Jesus, Christianity, Discipleship, Witnesses, Prisoners, Cipinang

\begin{abstract}
ABSTRAK
Setiap orang percaya dipanggil untuk menjadi murid oleh Kristus. Kekristenan tanpa pemuridan adalah kekristenan tanpa Kristus. Berangkat dari pernyataan ini, maka dipahami bahwa, hanya dengan menjadi seorang murid Kristuslah seseorang dapat menjadi terang atau saksi Kristus di dunia dan memimpin orang lain kepada Kristus. Kehidupan kekristenan yang sejati, tidak dimaksudkan dengan hanya sekedar menerima Yesus sebagai Juruselamat, menghadiri kebaktian gereja, membaca Alkitab, berdoa, berbicara tentang Yesus, tetapi juga dimaksudkan untuk mewakili Allah dan mendemonstrasikan gaya hidup kerajaan Allah di dunia. Jadi orang Kristen sejati adalah murid Yesus Kristus. Oleh karena begitu pentingnya pemuridan tersebut sehingga murid disebut 269 kali dalam Alkitab Perjanjian Baru, yang menunjuk pada individu-individu yang secara bersama-sama berkomitmen mengikuti Yesus Kristus. Tujuan penelitian ini adalah untuk memberikan pemuridan bagi narapidana Kristen yang berada dalam Lembaga Pemasyarkatan (selanjutnya disingkat Lapas) Cipinang Jakarta. Dengan menggunakan metode pendekatan secara kualitatif melalui pendekatan secara verbal kepada setiap narapidana yang berada dalam LAPAS Cipinang Jakarta Timur. Sebagai hasil dari penelitian ini bahwa setelah diadakan pemuridan ini
\end{abstract}

\footnotetext{
${ }^{1}$ Dosen program Pascasarjana Prodi Teologi SETIA Jakarta

2 Dosen Ketua Program Studi Teologi Magister Teologi SETIA Jakarta 2019
} 
para narapidana Kristen di Lembaga Pemasyarakatan Cipinang Jakarta Timur mereka memiliki karakter seperti Kristus, memiliki pengharapan kepada Kristus, dapat melipatgandakan pemuridan.

Kata Kunci: Yesus, Kekristenan, Pemuridan, Saksi, Narapidana, Cipinang

\section{PENDAHULUAN}

Menjadikan semua bangsa murid Kristus adalah tidak terlepas daripada peran murid Kristus untuk memberitakan Injil. Dengan demikian rencana penyelamatan Allah bagi dunia ini akan dapat terlaksana. Gereja yang adalah di dalamnya terdapat murid-murid Kristus itu sendiri dipilih dan ditetapkan Allah untuk menjadi alat-Nya. Menjadi kawan sekerja Allah untuk mewartakan kabar gembira kepada mereka yang tertindas yang lemah dan yang putus asa (Luk. 4:18-19).

Fakta yang mengagumkan bahwa sudah lebih dari 1900 tahun tujuan Allah itu belum tercapai. Tetapi fakta lain adalah bahwa Allah mempercayakan kelanjutan dan penyelesaian tugas itu kepada gereja. Namun perkembangan ini bukanlah sesuatu hal yang selalu berjalan mulus, kekristenan berkembang namun mendapatkan perlawanan dari pihak-pihak yang tidak menyukai karena masalah politik. Oleh karena itu, sebagai murid Kristus harus memiliki kesadaran akan peran penginjilan dan pemuridan untuk memperluas Kerajaan Allah dimuka bumi ini dan agar setiap suku bangsa mendapat bagian dalam karya penebusan Allah melalui Kristus Yesus. Semua orang Kristen memiliki tanggung jawab dalam penggenapan Amanat Agung Tuhan Yesus. Amanat Agung ini dapat dikerjakan dengan terlibat langsung sebagai penginjil ataupun sebagai mobilisator bahkan sebagai pendukung dalam doa. Jadi tidak ada alasan untuk tidak melibatkan diri dalam melaksanakan Amanat Agung Tuhan Yesus.

Pelayanan bagi kelompok narapidana adalah suatu pekerjaan yang mulia. Kemuliaanya adalah terletak daripada penjangkauannya dalam kehidupan yang termarginalkan oleh kalangan umum. Yesus sendiri memuji perbuatan manusia yang memedulikan kehidupan orang-orang yang dipenjara. "Dan Raja itu akan berkata kepada mereka yang di sebelah kanan-Nya: Mari, hai kamu yang diberkati oleh Bapa-Ku, terimalah Kerajaan yang telah disediakan bagimu sejak dunia dijadikan. Sebab ketika Aku lapar, kamu memberi Aku makan; ketika Aku haus, kamu memberi Aku minum; ketika Aku seorang asing, kamu memberi Aku tumpangan; ketika Aku telanjang, kamu memberi Aku pakaian; ketika Aku sakit, kamu melawat Aku; ketika Aku di dalam penjara, kamu mengunjungi Aku. Maka orang-orang benar itu akan menjawab Dia, katanya: Tuhan, bilamanakah kami melihat Engkau lapar dan kami memberi Engkau makan, atau haus dan kami memberi Engkau minum? Bilamanakah kami melihat Engkau sebagai orang asing, dan kami memberi Engkau tumpangan, atau telanjang dan kami memberi Engkau pakaian? Bilamanakah kami melihat Engkau sakit atau dalam penjara dan kami mengunjungi Engkau? Dan Raja itu akan menjawab mereka: Aku berkata kepadamu, sesungguhnya segala sesuatu yang kamu lakukan untuk salah seorang dari saudara-Ku yang paling hina ini, kamu telah melakukannya untuk Aku (Mat. 25:34-40).

Narasi dalam teks tersebut di atas memberikan suatu gambaran hidup yang dimas rapi oleh penulis Injil Matius yang menyampaikan suatu makna kepedulian terhadap sesama, bahkan yang termarginalkan sekalipun. Selain itu penulis juga ingin agar sekat-sekat dalam strata sosial digantikan dengan tirai kasih yang membentang dalam bingkai kehidupan manusia. Meskipun teks ini merupakan suatu perumpamaan yang disampaikan oleh Tuhan Yesus, namun hal itu sebenarnya merujuk kepada suatu pola hidup manusia pada akhir zaman bahkan sudah ada yang terjadi dalam zaman Yesus sehingga hal ini sangat relevan untuk dijadikan suatu acuan dalam pelayanan bagi narapidana secara khusus di Lapas Cipinang Jakarta Timur. 
Dapat dibayangkan akan suatu realitas hidup manusia yang semakin berada dalam pola hedonisme serta egosentrisme yang menonjol dengan tidak lagi peduli antara satu sama yang lain. Kasih manusia semakin akan menjadi dingin (Mat. 24:12). Kehidupan mansuia yang semakin modern, namun meninggalkan kasih yang sejati. Pada puncaknya manusia akan hidup dalam sistem materialisme dan mencintai diri sendiri (2 Tim. 3:2). Inilah suatu kenyataan hidup yang ada dalam peradaban manusia. Lalu bagaimana dengan kehidupan orang percaya, apakah akan ikut terseret dengan prinsip hidup mementingkan diri sendiri?

\section{METODE PENELITIAN}

Adapun metode penelitian yang digunakan dalam penelitian ini adalah sebagai berikut:

1. Sekolah Tinggi Teologi Injili Arastamar (SETIA) Jakarta mengajukan surat permohonan penelitian kepada Pimpinan Lembaga Pemasyarakatan Cipinang Jakarta Timur.

2. Setelah ijin diberikan oleh pihak Kepala Lembaga Pemasyarakatan Cipinang Jakarta Timur, peneliti mengadakan penelitian selama jangka waktu tertentu sampai data yang dikumpulkan sudah memadai.

3. Tempat penelitian adalah di Lembaga Pemasyarakatan Cipinang Jakarta Timur.

4. Data awal hasil dari penelitian selanjutnya diolah menjadi hasil penelitian.

\section{PEMBAHASAN}

\section{a. Pengertian Pemuridan}

Pemuridan adalah sebuah proses dimana seseorang dibentuk untuk menjadi murid sedangkan seorang murid adalah orang yang dalam segala bidang kehidupannya mencari kebenaran Alkitab dan menghayatinya secara konsekuen. Ia tidak membiarkan keadaan menentukan perbuatannya. Istilah murid adalah orang yang telah menjadi pengikut Tuhan dan rasul-Nya (1 Tes. 2:6). Pengertian kata murid menurut Alkitab, dalam bahasa Yunani disebut mathetes, merupakan arti sepadan dengan kata Kristen. Penggunaan paling umum dari kata matheles adalah untuk menunjukkan pada pengikut Yesus, orang-orang yang percaya bahwa Yesus adalah Tuhan dan juru selamatnya. Jadi seorang murid adalah seorang Kristen. Membuat murid adalah proses transformasi untuk membawa orang yang jauh kepada kedekatan dengan Kristus. Kata kerja menjadikan atau membuat murid (mathetheuin) dipakai empat kali dalam Perjanjian Baru (Mat. 13:53; 27:57; 28:19; Kis. 14:21). Proses membuat atau menjadikan murid yang efektif dan holistik adalah hanya dapat terjadi dalam konteks komunitas murid-murid Kristus yang telah dipanggil dari kegelapan kepada terang yang ajaib (eklesia). Dan pemuridan sendiri adalah proses atau perjalanan dinamis dari pertumbuhan pribadi yang holistik dengan, dan melalui Komunitas Kerajaan (Eklesia) baik dalam kehidupan individu maupun komunitas yang lebih luas.

Pemuridan juga merupakan latihan ketaatan sebagai seorang murid yang taat pada perintah gurunya. Jemaat yang sehat dan berkembang adalah merupakan hasil dari ketaatan atas perintah Tuhan yakni, menjadikan murid Kristus semua bangsa dan mengajarkan mereka apa yang diperintahkan Kristus kepada mereka (Mat. 28:18-20) dan juga yang telah menerima Roh Kudus serta kuasa-Nya untuk memberikan kemampuan kepada mereka menjadi saksi-Nya (Kis. 2:8). Orang-orang mulai memuridkan suatu bangsa, sekelompok orang, orang Yahudi bangsa mereka, dengan jalan menaati semua perintah Yesus. Ke-3000 orang yang percaya, mulai melakukan apa yang diperintahkan oleh Tuhan Yesus tanpa ditunda-tunda, mulai dari bertobat, 
percaya, menerima Roh Kudus, langsung diteguhkan dengan baptisan, melakukan perjamuan kudus, persekutuan, berdoa, memberi dan memuridkan dengan melakukan apa yang diajarkan oleh para Rasul dan bersaksi kepada orang lain. Hal ini menjadi model pemuridan dasar saat ini.

\section{b. Landasan Teologis Pemuridan}

1. Pola pelaksanaan pemuridan Tuhan Yesus sangat jelas Ia lakukan dengan mengunjungi pribadi-pribadi yang akan menjadi murid-Nya kelak. Ia mendatangi mereka dan memanggil mereka untuk menjadi pengikut-Nya. Yesus mengatakan, Dari buahnyalah kamu akan mengenal mereka" (Mat. 7:20). Buah-buah Roh dapat dijadikan ukuran untuk mengetahui apakah seseorang sungguh-sungguh telah menjadi seorang murid Tuhan atau belum.

Demikianlah kata Yesus kepada para murid-Nya: Karena itu pergilah, jadikanlah semua bangsa murid-Ku dan baptislah mereka dalam nama Bapa dan Anak dan Roh Kudus, dan ajarlah mereka melakukan segala sesuatu yang telah Kuperintahkan kepadamu. Dan ketahuilah, Aku menyertai kamu senantiasa sampai kepada akhir zaman (Mat. 28:19-20).

2. Pemuridan Paulus dalam 2 Timotius 4:2 dimana Timotius yang adalah murid Paulus telah menjadi gembala sidang di Efesus, tetap mendapat arahan dan petunjuk-petunjuk dari Paulus. Hubungan antara Paulus dan Timotius yang adalah anak dan orang tua. Sehingga Timotius sering disebut sebagai anak rohani Paulus. Prinsip pemuridan Paulus kepada Timotius adalah suatu prinsip hubungan yang akrab, seperti orangtua dengan anak.

Peter Wagner menyatakan bahwa di dalam Amanat Agung, ada empat kata kerja, yaitu, pergilah, jadikanlah murid-Ku, baptislah dan ajarlah. Dalam bahasa Yunani, dari keempat kata kerja tersebut hanya satu kata kerja yang merupakan bentuk perintah yaitu, jadikanlah murid$\mathrm{Ku}$. Malik Bambangan menyatakan bahwa, kata matheteusate adalah merupakan kata kerja imperativ aorist aktif orang kedua jamak dari kata matheteuo yang artinya menjadikan murid. Inilah yang disebut sebagai kata kerja utama yang berbentuk perintah sedangkan tiga kata kerja yang lainnya itu adalah merupakan bentuk partisip artinya penunjang kata kerja utama. Jadi, sasaran Amanat Agung adalah menjadikan orang lain sebagai murid Yesus dan inilah perintah Yesus kepada para murid-Nya. Dengan demikian Amanat Agung hanya akan terpenuhi jika setiap orang yang percaya, menjadi murid Yesus.

Istilah murid muncul sebanyak tiga kali, istilah orang percaya dua kali. Hal ini memberikan indikasi bahwa tugas gereja tidak hanya sekedar menjadikan orang Kristen atau orang percaya, melainkan menjadikan murid. Seorang percaya harus memenuhi persyaratan Yesus Kristus didalam Lukas 14:25-33, namun pada masa kini tidak semua orang adalah murid. Murid berarti seseorang yang belajar dan menerima pengajaran Kristus bukan hanya dalam kepercayaan melainkan juga dalam gaya hidup. Alkitab mengatakan bahwa orang percaya berada dalam medan peperangan rohani (Ef. 6:12). Setiap orang percaya hanya akan dapat bertahan jika mengikut Tuhan Yesus sebagai murid-murid-Nya. Perjanjian Baru memberikan contoh mengenai kelompok pemuridan, yaitu Yesus dan duabelas orang murid (Mrk. 3:14-15); Yesus dan tiga murid (Mat. 17:1; Mrk. 9:2; Luk. 9:28); Yesus dan tujuhpuluh murid (Luk. 10 :1-11). Jemaat mula-mula (Kis. 2:42-46).

\section{c. Teori Pemuridan}

1) Definisi Pemuridan.

Murid-murid Yesus adalah orang-orang yang telah dilahirkan kembali oleh Roh Allah. Orangorang itu telah mengaku dengan mulutnya bahwa Yesus adalah Tuhan, dan percaya dalam 
hatinya bahwa Allah telah mengbangkitkan Dia dari antara orang mati (Rm. 10:9-10). Ada beberapa definisi tentang pemuridan, antara lain:

a) Menurut Tomatala, pemuridan adalah proses membawa orang kepada Kristus, melibatkan dia kedalam kehidupan jemaat untuk bertumbuh dan bertambah dalam iman, yang pada gilirannya ia akan memuridkan orang lain.

b) Menurut Rick Warren, pemuridan adalah proses untuk menolong orang menjadi lebih seperti Kristus dalam pikiran, perasaan dan tindakan mereka. Proses ini dimulai ketika seseorang dilahirkan kembali dan terus berlanjut disepanjang sisa hidupnya.

c) Menurut Garyl L. Mclntosh, pemuridan adalah proses untuk menemukan dan memenangkan orang yang terhilang, menyatukannya ke dalam gereja lokal atau membangun orang-orang itu didalam iman. Jadi dari beberapa definisi yang dipaparkan, dapat ditarik kesimpulan bahwa pemuridan adalah proses menjadikan seseorang murid Kristus sehingga memiliki kehidupan yang terus bertumbuh menuju kedewasaan seperti Kristus dan pada gilirannya akan memuridkan orang lain.

d) Menurut Michael K. Shipman, pemuridan adalah menjangkau dan sekaligus menjemaatkan (membuat orang yang dijangkau menjadi jemaat). Percaya dan dibaptis adalah langkah pertama menjadi murid Yesus, proses selanjutnya yaitu berkumpul sebagai jemaat kemudian mempunyai kesempatan untuk menaati semua perintah Yesus yaitu menjadi murid-Nya, jadikanlah semua suku bangsa murid-Ku, berarti menjangkau (termasuk membaptis) dan menjemaatkan setiap suku bangsa. Sebelum diangkat ke surga, Yesus menyatakan rencana revolusioner untuk memuridkan, yaitu menjangkau dan menjemaatkan setiap suku bangsa di dunia oleh murid-murid-Nya. Rencana Yesus itu sederhana yaitu setiap orang percaya menjadi imam (1 Ptr. 2:9-17), yang melakukan setiap dari tiga tugas keimaman, agar setiap suku bangsa dijangkau dan dijemaatkan. Setiap dari tiga tugas keimaman adalah:

(1) Setiap orang percaya pergi memberitakan Injil

(2) Setiap orang percaya membaptis orang yang dijangkaunya

(3) Setiap orang percaya melatih orang yang dijangkau untuk merintis jemaat rumah, diajar untuk menaati semua perintah Yesus.

Memuridkan semua suku, menyangkut penjangkauan dan perintisan, pengembangan jemaat, serta pendidikan dan pelatihan para pemimpin jemaat dan jaringan jemaat baru.

2) Prinsip Pemuridan

Prinsip pemuridan ditekankan oleh ilustrasi yang dipakai oleh Para Navigator yang dinamakan Roda yang dikutip dari buku Cara Melatih Murid Kristus oleh Henrichsen. Roda adalah lukisan orang Kristen yang berpusat pada Kristus dan yang hidup dalam ketaatan. Roda tersebut dapat lihat dalam gambar berikut ini beserta dengan penjelasan pengertian masing-masing.

\section{Strategi Pemuridan bagi Narapidana LP Cipinang}

\section{Membangun Komunikasi}

a. Petugas Lapas

Pada saat melayani seseorang, maka panggilan Allah tersebut dapat dimaknai sebagai strategi dalam melayani Tuhan. Strateginya adalah sebagaimana Yesus memberikan pengajaran kepada para murid-Nya. Markus 3:27 "Tetapi tidak seorang pun dapat memasuki rumah seorang yang kuat untuk merampas harta bendanya apabila tidak diikatnya dahulu orang kuat itu. Sesudah itu 
barulah dapat ia merampok rumah itu."Berdasar pada firman inilah kami mengadakan pola pendekatan untuk menjangkau para narapidana Kristen dalam Lapas Cipinang. Maka dari peneliti mengadakan pendekatan dalam arti pelaporan diri serta kegiatan yang dimaksudkan dalam peneltian ini agar dapat diterima serta dilegitimasi oleh pihak Kalapas Cipinang Jakarta Timur. Ini merupakan strategi penjangkauan kepada setiap oknum yang akan dilayani sehingga memudahkan peneliti dalam menjalankan program penelitian.

\section{b. Narapidana}

Pendekatan yang dimaksud dalam bagian ini adalah untuk mendaratkan maksud dan tujuan dalam penelitian ini. Peneliti mengadakan pendekatan kepada setiap narapidana sehingga kelak ketika program ini berjalan tercipta suatu suasana yang harmonis. Mengapa hal ini perlu dalam menjangkau para narapidana? Karena para narapidana mungkin ada yang merasa tidak lagi dihargai oleh orang lain. Dengan mengangkat derajat mereka akan memudahkan peneliti untuk masuk dalam pelayanan sebagai langkah praktis dan taktis bagi pemuridan itu sendiri.

\section{Penginjilan Pribadi}

Setelah mengadakan pendekatan bagi setiap narapidana,maka Langkah selanjutnya adalah mewartakan Injil Kristus bagi mereka, tentu sudah dibatasi diawali bagi narapidana Kristen. Pemberitaan Injil yang juga disebut kabar baik bagi para narapidana Kristen adalah suatu hal yang sangat penting karena mereka membutuhkan suatu kepastian hidup setelah menjalani vonis dari hakim. Pemberitaan Injil bagi mereka merupakan suatu peluang yang luar biasa. Bahwa mereka juga masih punya harapan untuk masa depan. Dengan demikian pelayanan pemberitaan Injil bagi mereka akan menghapus "stigma" selama ini bahwa, "seorang mantan napi tetap narapidana yang pada akhirnya tidak lagi memiliki masa depan.

Ketika rasul Paulus berada dalam penjara, ia banyak menjangkau para tahanan yang lainnya dan dibawa kepada Kristus. Demikian juga Ketika Paulus dalam penjara di Kaisarea Filipi, dalam pemberitaan Injiil kepada kepada penjara di Kaisarea Filipi menjadikan kepala penjara tersebut mengalami pertobatan dan menerima Kristus sebagai juru selamatnya beserta seluruh isi rumahnya (Kis.16:19-34).

Dalam kitab Filemon rasul Paulus menuliskan suatu peristiwa yang luar biasa dalam kitab Filemon 1:10 mengajukan permintaan kepadamu mengenai anakku yang kudapat selagi aku dalam penjara, yakni Onesimus. Ayat ini mengindikasikan bahwa Paulus telah berhasil memuridkan Onesimus selagi ada dalam penjara. Bahkan Paulus juga menjadikan hidup Onesimus menjadi berarti kembali baik bagi Filemon secara pribadi, maupun kepada pelayanan secara umum. Paulus menuliskan kepada Filemon demikian; "Sebab mungkin karena itulah dia dipisahkan sejenak dari padamu, supaya engkau dapat menerimanya untuk selama-lamanya, bukan lagi sebagai hamba, melainkan lebih dari pada hamba, yaitu sebagai saudara yang kekasih, bagiku sudah demikian, apalagi bagimu, baik secara manusia maupun di dalam Tuhan (Fil. 1:1516).” Dasar pelayanan inilah menjadi acuan untuk mengadakan PI pribadi dalam Lapas Cipinang Jakarta Timur agar dapat menjangkau dan menjadikan para Narapidana di sana sebagai murid Kristus Yesus.

\section{Kepribadian Pelayan}

Strategi pemuridan dalam penjara Cipinang adalah ditopang dengan adanya suatu kepribadian yang tulus dan baik dalam pelayanan ini. Untuk dapat memuridkan orang lain, maka sangat ditentukan oleh kepribadian seseorang yang memiliki hati dan motivasi yang jujur dihadapan 
Tuhan dan manusia yang tidak bercacat dan bercela. Kepribadian akan terbangun dari kerohanian serta panggilan seseorang untuk pelayanan pemuridan bagi mereka yang termarginalkan. Jika suatu kepribadian terbangun dari dasar yang kuat, maka hal itu akan melahirkan suatu dampak yang lauir biasa bagi orang lain. Hal inilah yang dilakukan dalam melaksanakan pola pemuridan bagi narapidan Kristen dalam Lapas Cipinang Jakarta Timur. Sehingga Ketika mereka bebas nanti, merekapun dapat diterima oleh keluarga,dan masyarakat pada umumnya. Tujuan pemuridan ini adalah untuk memberikan motivasi serta dukungan moral kepada setiap narapidana supaya mereka tetap aktif dalam setiap proses pembentukan bagi mereka selama di Lapas dan pada akhirnya Ketika mereka bebas, mereka dapat mencari pekerjaan dimanapun yang sesuai dengan minat dan bakat mereka.

\section{Membangun Persekutuan}

Ketika sudah mendapatkan jiwa-jiwa yang dari hasil PI Pribadi, maka hal yang terpenting dilakukan adalah membawa jiwa-jiwa tersebut ke dalam suatu persekutuan Kristen sebagai agenda dalam program pemuridan. Membangun persekutuan dalam Lapas ini dimaksudkan bukan hanya persekutuan dalam arti perkumpulan massa, namun hubungan setiap narapidana kepada Tuhan perlu terus dibangun meskipun mereka dalam suasana yang tidak menguntungkan secara duniawi. Pola hubungan keakraban perlu terus dibangun sehingga setiap narapidana tidak merasa asing atau kesepian. Sikap merasa asing dan kesepian seringkali terjadi dan berakibat fatal bagi para narapidana karena berujung pada Tindakan bunuh diri. Informasi ini didapatkan oleh tim peneliti dari beberapa narapidana yang dilayani. Adapun persekutuan diadakan beradasarkan jadwal yang sudah dietapkan oleh bidang kerohanian Lapas Cipinang Jakarta Timur. Dan akhirnya persekutuan dapat dilaksanakan dua kali dalam seminggu, itupun menyesuaikan dengan kondisi dalam Lapas dan keadaan yang insidentil sehingga tidak memberatkan bagi para narapidana.
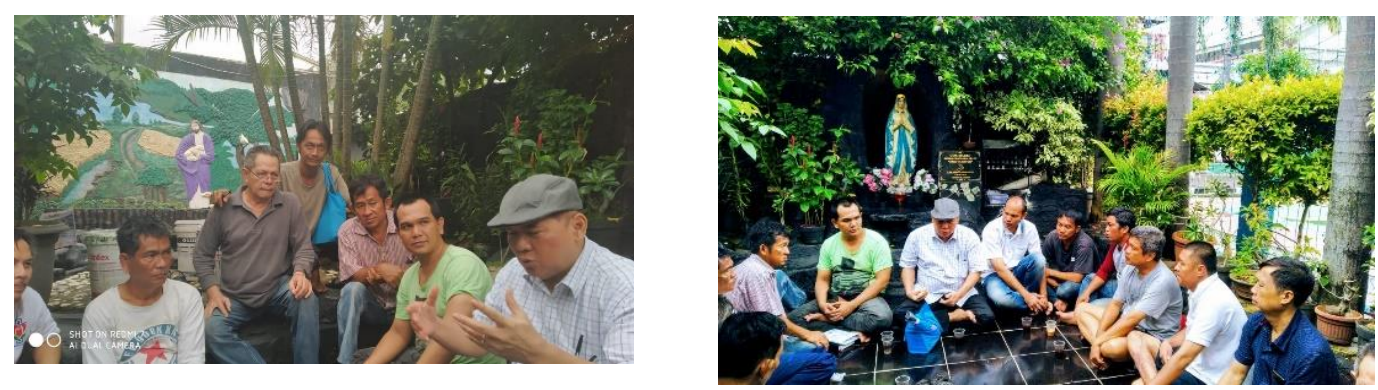

Gambar 1. Persekutuan di dalam Lapas Cipinang

HASIL

Sebagi hasil dalam pemuridan ini adalah bahwa hal ini telah mencapai tujuan Pemuridan yaitu menolong setiap orang menjadi dewasa di dalam Kristus secara khusus bagi para narapidana di Lapas Cipinang Jakarta Timur. Hal ini berarti bahwa setiap pribadi makin menyerupai Kristus dalam perkataan dan perbuatan. Seseorang yang memuridkan tidak ubahnya seperti seorang gembala bagi domba yang harus mengenal dan memimpin setiap dombanya bahkan mengawasi, menjaga dan memperhatikan kesejahteraan orang-orang itu dengan kasih Kristus. Melalui pembuat murid, Roh Kudus memberi pertumbuhan rohani orang-orang yang sedang di muridkan 
dengan belajar Firman Tuhan dan berdoa. Berikut ini beberapa hal yang dihasilkan dari pemuridan tersebut yakni:

1. Memiliki karakter seperti Kristus.

Orang-orang percaya berada di dalam Kristus. Sekurang-kurangnya terdapat dua ayat yang memuat konsep bahwa orang percaya ada di dalam Kristus dan Kristus ada di dalam orangorang percaya yaitu Yohanes 6:56 tentang barang siapa makan daging-Ku dan minum darah-Ku, ia tinggal di dalam Aku dan Aku di dalam dia, Yohanes 15:4 tinggalah di dalam Aku dan Aku di dalam kamu. Kelahiran baru adalah tindakan Roh Kudus dan Roh Kudus membawa seseorang kedalam kesatuan dengan Kristus dan juga mendukung, mengisi dan menyempurnakan keseluruhan proses keselamatan. Orang percaya mendapatkan manfaat kesatuan dan terus hidup di dalam kesatuan itu melalui iman. Melalui iman, orang percaya dikuduskan yang artinya sedang diperbaharui oleh kesesuaian dengan gambar Allah (Rm. 8:29). Tujuan Allah dalam pemilihan adalah menjadikan orang-orang yang percaya kepada-Nya serupa dengan anak-Nya dan dengan demikian serupa dengan Bapa.

2. Kebergantungan kepada Kristus.

Kebergantungan manusia yang nyata adalah bahwa manusia ciptaan Allah sehingga setiap pengertian dan pengetahuan yang benar dalam segala hal yang didapatkannya berasal dari Allah. Setiap narapidana yang berada dalam Lapas akan bergantung sepenuhnya kepada Kristus meskipun mereka tidak lagi diperhatikan oleh keluarga, namun mereka berharap kepada Tuhan yang menolong mereka. Bahkan setelah mereka lepas nanti, mereka akan tetap berharap kepada Tuhan dan bukan mengandalkan manusia.

\section{Pelipatgandaan.}

Jemaat yang sehat akan berkembang dari ketaatan atas perintah-Nya. Para rasul memulai gereja yang mula-mula dalam Perjanjian Baru di kota Yerusalem untuk menjadikan semua suku bangsa murid Kristus sekaligus mengajarnya. Para rasul mulai memuridkan bangsa Yahudi dari pertobatan, pembaptisan, perjamuan kudus, bersekutu, berdoa, memberi dan memuridkan. Hal itu menjadi model untuk pemuridan dasar masa kini. Pelipatgandaan jemaat di dalam kuasa Roh Allah membutuhkan jemaat yang sedang berkembang, yang dengan sadar mengikuti teladan para rasul yang memuridkan para murid yang taat untuk melakukan perintah Kristus. Berhubungan dengan pelipatgandaan adalah adanya pertambahan jumlah orang percaya baru yang dihasilkan oleh murid Kristus berdasarkan Amanat Agung-Nya. Perintah untuk pergi memberitakan Injil adalah peristiwa yang sudah melalui proses panjang selama kurang lebih tiga setengah tahun para murid telah dipersiapkan dalam segala situasi (Mat. 24:14). Momen pengutusan ini menjadi penentu masa depan pelayanan para murid Kristus ketika Kristus akan anaik ke surga (Yoh. 14:28-29).

\section{KESIMPULAN}

Pelayanan pemuridan bagi para narapidanan Kristen di Lapas Cipinang Jakarta Timur adalah suatu pelayanan yang sangat relevan bagi para hamba Tuhan masa kini. Pelayanan yang bermuara kepada penjangkauan orang-orang yang mungkin dianggap tidak berarti di mata masyarakat kini menjadi percaya diri bukan saja untuk masyarakat secara umum, namun secara khusus berarti bagi pekerjaan Tuhan jika mereka berkomitmen melayani Tuhan melalui metode pemuridan ini. Dengan demikian 


\section{SARAN}

Dalam penelitian ini kami memberikan saran-saran praktis untuk dapat ditindaklanjuti oleh para aktivis gereja, Yayasan Kristen dan sekolah Kristen serta gereja sebagai berikut:

Pertama, Bagi para hamba Tuhan atau gereja yang belum memiliki program pelayanan ke penjara, agar dapat didiskusikan dalam komunitas gereja untuk pelayanan tersebut.

Kedua, Pelayanan dapat dilakukan dengan mengadakan bakti social seperti; pengobatan gratis, membagi sembako, serta pelayanan lainnya. Kegiatan ini dapat dilakukan secara bersamasama dengan beberapa kelompok lainnya yang memiliki passion yang sama dalam melayani Tuhan.

Ketiga, Pelayanan untuk kebaktian setiap minggu dalam Lapas, karena ada kegiatan ibadah setiap minggu. Kegiatan pelayanan dapat juga dilakukan melalui penginjilan pribadi agar para narapidana Kristen didalam Lapas tersebut tidak kehilangan pengharapan iman.

Keempat, Gereja juga dapat melakukan pembagian pakaian layak pakai bagi para narapidana untuk membantu mereka di dalam sana. Ini juga menjawab panggilan Yesus untuk memedulikan sesama yang di dalam penjara sekalipun.

\section{DAFTAR PUSTAKA}

Garyl L. Mclntosh. Biblical Church Growth. Malang: Gandum Mas. 2012.

George Patterson, Richard Scoggins. Pedoman Pelipat Gandaan Jemaat. Pasadena California: William Carey Library. 2006.

George Patterson, Richard Scoggins. Pedoman Pelipatgandaan Jemaat. Pasadena California: William Carey Library . 2006.

George Patterson. Pedoman Pelipatgandaan Jemaat. Bandung: Yayasan Kalam Hidup. 2002.

H. Venema. Injil Untuk Semua Orang. Jakarta: Yayasan Komunikasi Bina Kasih. 1974.

J. I. Paker. Penginjilan Dan Kedaulatan Allah. Surabaya: Momentum. 2003.

J. Marvin Leech. Pemuridan III Semarang. Semarang: STTBI. 1995.

J. Oswald Sanders. Spiritual Discipleship. Cicago: Moody Press. 1994.

John R.W. Stott, Johannes Verkuyl, dkk. Misi Menurut Perspektif Alkitab. Jakarta: YKBK, 2007.

Michael K. Shipman. Amanat Agung Asli. Semarang: RAHAYU Group. 2014.

John Stott. Murid Radikal yang Mengubah Dunia. Surabaya: Perkantas. 2013.

Living Spring Kairos. Filipina: LSI. 2004.

Malik. Eksegetis Matius 28:16-20; Tesis. Batu: STT “I-3”, 2012.

Malik. Pelaksanaan Pemuridan dalam Gereja Masa Kini, Jurnal MIDRASH Volume 1 Nomor 1 Edisi

Januari-Juni 2016; ISSN 9772302797001. Purwokerto: STT Diakonos. 2016.

Michael K. Shipman. Amanat Agung Asli. Semarang : RAHAYU Group. 2014.

O.J Gibson. Living Discipleship Principle. Kansas: Walterick Publishes. 1995.

Peter Wagner. Strategi Perkembangan Gereja. Malang: Gandum Mas. 1999.

Peter Wongso. Tugas Gereja Dan Misi Masakini. Malang: Departemen Literatur SAAT. 1999.

Rick Warren. The Purpose Driven Church. Michigan: Zondervan Publishing House. 1995.

Stan Toler \& Glen Martin. Survival Skills. Jakarta: Metanoia Publishing. 2003.

Stephen Tong. Dosa, Keadilan dan Penghakiman. Surabaya: Momentum. 2009.

Steve Baker, Judy Johnson, Jimmy Long, Rob Malone, Ron Nicolas(Illinois: Inter Varsity Press Downers, 1994). Buku Pegangan Pemimpin Kelompok Kecil, (Surabaya: Perkantas)

Tim Penyusun, World Map. Pedoman Pelatihan Bagi Jiwa Baru, (Jakarta : International Christian Mission, 1993)

Walter A. Henrichsen, Cara Melatih Murid Kristus, (Bandung: Kalam Hidup, 1994)

Yakob Tomatala, Teologi Misi, (Jakarta: Leadership Foundation, 2003) 